\title{
ON THE DISPOSAL OF DISPOSABLES
}

\author{
Lieutenant-Colonel H. M. RAYNER \\ M.R.C.S., L.R.C.P., R.A.M.C. \\ Army Work Study Group
}

Introduction

THERE is a rapidly increasing utilisation of disposable items in all types of medical units. Although a great deal of thought has been directed to the economics and logistics of this innovation there is one aspect which has, so far, received little attention in this country. This is the method for disposing of disposables. The importance of this depends on the volume used: In the United States of America, where disposables are being used on a vast scale, the question of disposal has already become the major problem facing the users. In this country the use of disposables has not yet reached this magnitude, but cannot be far off: At first sight, it might seem surprising that there should be any problem: it is the intention of this paper to outline the special characteristics which make disposal difficult.

\section{Why Disposables?}

It has been contended that no matter how well a used article may be cleansed and resterilised it may still carry a residue of infective (or allergenic) material. It follows that the only sure way of preventing cross-infection is to destroy items after only one use. If this argument is to be accepted, as it surely must be, then it must also be accepted that every used article is potentially infected; therefore destruction by burning is indicated, and this is the traditional way of dealing with hospital waste-a way which avoids all difficulties with Local Authorities.

\section{Nature of Disposables}

Disposable items are fabricated from plastics alone or from paper or glass-fibre bonded by plastic material. They replace items made from glass, metal, natural fibres (cotton, etc.), natural sponges and ceramics. The attractive attributes of the synthetic resins and synthetic resin bonded laminates, vis-a-vis traditional materials, include: (a) cheapness. (b) lightness. (c) lower fragility. $(d)$ chemical inertness. (e) better thermal properties. $(f)$ quietness during handling. $(g)$ aesthetic consideration, e.g. texture and colour.

The cheapness and lightness, all other things being equal, permit the "use once only, then throw away" concept to be practical.

\section{The Materials}

Plastics may be divided into two main classes: the thermosetting and the thermoplastic ( there is, now, a third class which does not solidify, but this will not be encountered in a sufficient quantity to pose any problem). Of the hundreds of resins now available only those in use or likely to be used in the medical context will be named.

\section{Thermosetting Plastics}

These are produced as granules or as a slurry in a partially cured state. This is placed in a press and final curing and moulding are achicved at one operation by the application of pressure and heat. Once formed, they are hard and have lost their plasticity. This class includes: phenol-formaldehyde (bakelite), urea-formaldehyde (Beetle) and melamine formaldehyde (Melaware). They are used for ashtrays, tableware and cutlery. 


\section{Thermoplastic Plastics}

These are produced as granules, rods, sheets or films in the fully cured state. They are then shaped by heating them to the softening point and pressing, vacuum forming, blowing or injection moulding. The distinctive feature is that they remain capable of being softened by heat. This is a large class which includes: cellulose triacetate (Cellophane, Rayon); the Vinyl group (Polyvinyl chloride, polyvinyl acetate and polyvinylidene); the Acrylic group (Perspex etc.); polystyrene ; polyetnylene; polyurethane; polypropylene; polyamide (Nylon) and polyethylene terephthalate (Terylene, mylar and melinex). They are made into bottles, stoppers, jugs, bowls, dishes, gallipots, syringes, funnels, tubing, forceps, waterproof sheets, foam pads, catheters, recording and adhesive tape, suture materials, draping films, woven cloths and, of course, the ubiquitous ' polythene bag '.

\section{Behaviour in the Incinerator}

Non-plastic supporting fibres, in laminates, burn normally. The thermosetting group presents no difficulties since they first char then burn into carbon dioxide and water vapour so long as a sufficiently high temperature is available.

The thermoplastic group causes major problems. Because of their thermoplasticity these materials melt in the incinerator. In small quantities this can cause no trouble especially if the plastic is fed in with a larger volume of non-plastic material; but if a large quantity of thermoplastic is introduced into an incinerator the molten mass can dowse the flame by covering the jets $\mathrm{cr}$ by blocking the air inlets. Indeed the molten plastic may pour out of low air inlets. Once the flame is out nothing can be done until the fire-box has cooled, by which time the plastic will have solidified. Most of these plastics oxidise to carbon dioxide and water vapour on combustion, but there is an important exception in the case of those materials which contain a halogen. Polyvinyl chloride (P.V.C.) numbers hydrochloric acid gas and carbonyl chloride (phosgene) amongst its products of combustion. The hydrochloric acid gas attacks the metalwork of the incinerator and flue-pipe, and there are American reports of severe corrosion due to this cause. The properties of phosgene are too well known to need detailing here. These special properties do necessitate some re-thinking about the design of incinerators.

\section{Design of Incinerators}

It is clear that any incinerator which is expected to cope with large volumes of plastic waste will have to be built with the flame directed downwards from above the level of the mass to be destroyed, also air inlets will have to be at a high level furthermore any ash-box door will have to make an efficient seal with the main body in order to forestall the difficulties caused by the melt.

The noxious gases are a separate problem. The hydrochloric acid gas will necessitate the protection of metalwork throughout by refractory materials such as brick or specially developed plastic (!) linings which will withstand the temperature and resist the corrosive attack. The presence of phosgene in the flue gases indicates the use of a tall chimney or forced extraction through a filter. Without doubt, such incinerators are going to be expensive items, and it is worthwhile to examine possible alternatives.

\section{Alternative Methods of Disposal}

For health reasons the Local Authority refuse collectors cannot be expected to handle raw waste, unless it is sealed in impervious containers. Unfortunately most disposable items are hollow and occupy a large volume. There are machines which will shred or crush these items before they are baled. This reduces the volume to be handled, 
and the concentration presents no weight problem because of the inherent low density of all plastic materials (the specific gravity varies between 1.1 and 1.7 , that is about half the weight of aluminium). The disadvantage of this system is the cost of the crushing/shredding machinery. Also, most Local Authorities would demand the separation of parts such as hypodermic needles.

One other alternative makes use of the very characteristic which causes the difficulty. This is the use of relatively low temperature ovens to melt down the plastic in special pans. When cool, the block, thus cast, would be extracted from the mould-pan. These blocks could be removed to a central specially constructed incinerator for destruction. This would be safe because the melting-down process would entrap most of the infective material within the mass of material. The densities are such that any infective material which escaped entrapment would float to the top, where it could be dealt with by a strong disinfectant. This, of course, is only possible for thermoplastic materials, and would entail a preliminary stage to separate out the thermosetting plastics. These would be incinerated in the normal way, since they present no problems.

One final method must be mentioned. It has been suggested that if plastics could be dissolved they could be poured down the drain. In the present state of the art those plastics which can be dissolved each require different solvents, and represent only a small fraction of those in use. However, recent advances in fluorine chemistry suggest that a universal solvent may be available in the near future. It is probable that any such solvent will be toxic, and it is certain that it will be expensive: therefore, any practicable process must involve a closed circuit with solvent recovery and recycling.

\section{Conclusion}

The large scale disposal of plastics poses new problems which are formidable but not insurmountable.

In the short term the solution would seem to be either local incineration in specially designed incinerators or local casting backed up by centralised incineration.

In the long term: this is a problem which is not confined to medicine; it will involve the whole of industry and domestic users as well, although they will not have the infection aspect to consider. It is, perhaps, not too wildly imaginative to envisage the time when plastic waste disposal becomes an industry in its own right.

This paper does not imply any criticism of the " use once only; then throw away" principle: it is merely a warning that the "throw away" aspect is just not quite so simple as it might appear to be.

\section{ERRATUM}

Volume 112, Issue No. 1, 1966.

Page 65-under "Rickettsial Diseases", paragraph two, line one, for Major Barker read Parker. 